VINCENT, S. B. The white rat and the maze problem. II. The introduction of an olfactory control. Joumal of Animal Behavior, 1915b, 5 , $140-157$.

WODINSKY, J., VARLEY, M. A., \& BITTERMAN, M. E. Situational determinant of the relative difficulty of simultaneous and successive discrimination. Journal of Compara- tive \& Physiological Psychology, 1954, 47, 337-340.

\section{NOTE}

1. Based on a thesis submitted to the University of Arkansas by the first author in partial fulfillment of the requirements of the Master of Arts degree.

\title{
Schedule-induced polydipsia: Effects of providing an alternate reinforced response and of introducing a lick-contingent delay in food delivery'
}

\begin{abstract}
EVALYN F. SEGAL, University of Illinois at Chicago Circle, Chicago, Ill. 60680 and DAVID L. ODEN, University of Pennsylvania, Philadelphia, Pa. 19104
\end{abstract}

In Experiment 1, rats exhibited polydipsia on a concurrent spaced-response, variable-ratio schedule of reinforcement for bar presses on two bars, indicating that even the availability of a reinforcement schedule $(V R)$ that encourages high and steady bar-pressing rates does not eliminate the polydipsia induced by the spacing of food. In Experiment 2, rats developed polydipsia in response to a spaced-food schedule, even though every water lick delayed food delivery for 30-60 sec, indicating that the development of polydipsia does not depend on adventitious food reinforcement.

\section{EXPERIMENT}

Earlier studies have indicated that polydipsia will occur whenever fooddeprived $S s$ are exposed to a food-delivery schedule that delivers a food pellet at a spacing greater than about $20 \mathrm{sec}$, whether or not food deliveries are contingent on the emission of an operant response (Burks, Hitzing, \& Schaeffer, 1967; Clark, 1961; Deadwyler \& Segal, 1965; Falk, 1961a, b, 1964, 1966a, b, c, 1967, in press; Kaplan, 1965; Lester, 1961; Malott \& Cumming, 1965; Salzberg, 1967; Salzberg\& Schaeffer, 1968; Schaeffer \& Diehl, 1966; Schaeffer, Diehl, \& Salzberg, 1966; Schuster \& Woods,
1967; Segal \& Bandt, 1966; Segal \& Holloway, 1963; Segal, Oden,\& Deadwyler, 1965; Stein, 1964). Schedules that provide food deliveries very close together, however, do not usually elicit polydipsia. Small fixed-ratio, fixed-interval, or variableinterval bar-pressing schedules do not cause polydipsia, nor does a continuous reinforcement schedule, nor do free-food schedules that deliver food as often as every $20 \mathrm{sec}$. The fact that polydipsia occurs only when the spacing of food deliveries reaches some minimum time interval suggests that the drinking might partly be accounted for by the animal's impatiently filling time with some behavior that makes waiting for the next food delivery tolerable. This suggestion is weakened by the fact that rats will exhibit polydipsia on schedules, such as a variableinterval bar-press reinforcement schedule, that might be thought to encourage the rat to fill time by bar pressing. It is weakened further by the finding (Segal, in press) that polydipsia will occur even when an alternate response (wheel running) is available to the animal to fill time with. Finally, the present data weaken the time-filling hypothesis still further by showing that polydipsia occurs even when a reinforced alternate response (bar pressing on a variable-ratio schedule) is available, and even when the reinforcement schedule is one that encourages high and steady rates of bar pressing-which might be thought to leave no empty time to be filled with drinking.

\section{Method}

One male, young adult, albino rat was maintained at $80 \%$ of ad lib weight by a food-deprivation regimen, and exposed for several sessions to a concurrent DRL 20-sec VR 23 bar-pressing schedule on two levers. Presses on one lever were reinforced if they were spaced at least $20 \mathrm{sec}$ from the preceding press on that lever (DRL $20 \mathrm{sec}$ ); presses on the other lever were reinforced after a variable number of presses, averaging 23 , was emitted. The reinforcers were 45-mg Noyes rat chow pellets, and sessions lasted until 150 reinforcers had been received. A water bottle was available.

Results

Figure 1 shows typical results from Session 11. Presses on the DRL bar occurred at the low, steady rate characteristic of performance on spaced-response DRL schedules. Presses on the VR bar occurred at the high and fairly steady rate characteristic of performance on variable-ratio schedules. Nevertheless, a polydipsic level of drinking occurred. The drinking was not so persistent, however, as on a simple DRL 20-sec schedule (e.g., see the figure in Segal

\section{RAT 5 - DRL 20 VR 23 - DAY \|}
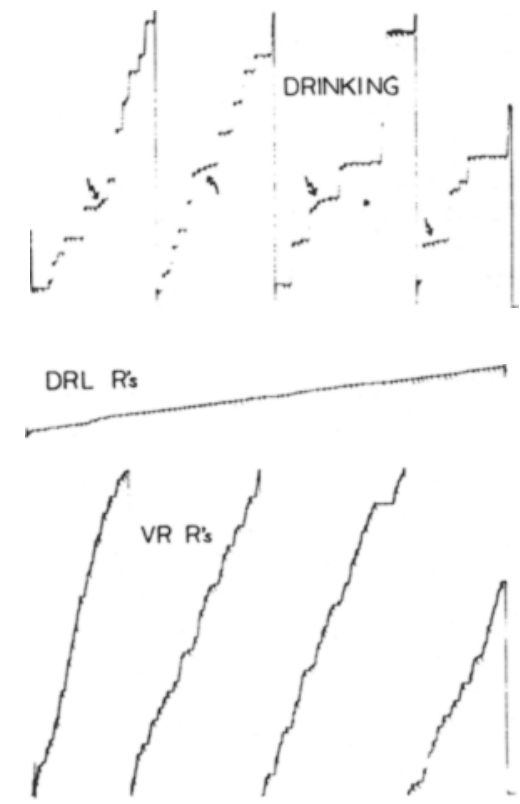

Fig. 1. Cumulative licks (upper tracing), cumulative bar presses on the DRL (spaced response) bar (middle tracing), and cumulative bar presses on the VR (variable ratio) bar (lower tracing), in Session 11 of concurrent DRL 20-sec VR 23. Each full excursion of the pen represents about 500 responses. Downward deflections in the drinking record indicate DRL bar presses; in the other two records they indicate reinforcements on the respective schedules. 
\& Holloway, 1963). That introducing the competing, and alternate, reinforced behavior of variable-ratio bar pressing somewhat reduced the level of polydipsia generated by the spacing of food on the spaced-response (and variable-ratio) schedule does not detract from the point that polydipsia must be something more than time filling, for variable-ratio responding would have filled time as well.

\section{EXPERIMENT 2}

Falk (1964, in press) showed that introducing a delay of $15 \mathrm{sec}$ between a water lick and the availability of food reinforcement did not eliminate, or even reduce, the level of polydipsia generated by a variable-interval 1-min bar-press reinforcement schedule. However, it is barely conceivable that a food pellet arriving even so long as $15 \mathrm{sec}$ after a water lick might still have some power to reinforce licking, or at least to add some reinforcement contribution to the factors generating and maintaining schedule-induced polydipsia. In Experiment 2, therefore, we introduced longer delays: $30 \mathrm{sec}$ for two rats, and $60 \mathrm{sec}$ for two others.

\section{Method}

Eight male, young adult, albino rats, maintained at $80 \%$ of ad lib weight by a food-deprivation regimen, were exposed for several sessions to a free-food schedule that delivered one 45-mg Noyes rat chow pellet every $60 \mathrm{sec}$ in sessions lasting until 50 pellets had been delivered. The experimental chamber included a water bottle, attached to a Grason-Stadler drinkometer.

The rats were divided into four pairs, each pair consisting of an experimental rat and a yoked control rat. Two of the experimental rats were exposed to a lick-delay contingency, superimposed on the 60-sec free-food schedule, of $30 \mathrm{sec}$. That is, every lick at the water bottle postponed food delivery for $30 \mathrm{sec}$. Their yoked controls received food in a separate chamber simultaneously with the receipt of food by the experimental rats. The other two experimental rats were exposed to a 60-sec lick-delay contingency, and their yoked controls received a pellet whenever, and only whenever, their experimental partners did. Because of the lick-delay contingency, the spacing of food deliveries was not precisely $60 \mathrm{sec}$ for any rat. It was always at least $60 \mathrm{sec}$, but might be more, depending on the licking of the experimental rats.

\section{Results}

Figure 2 shows the number of water licks per in terpellet interval for each of the rats, in each of the sessions. Polydipsia developed whether or not water licks postponed food. However, in three of four cases, the level of drinking was slightly lower in experimental rats than in their yoked controls, suggesting that preventing a close temporal correlation between a water lick and the arrival of food

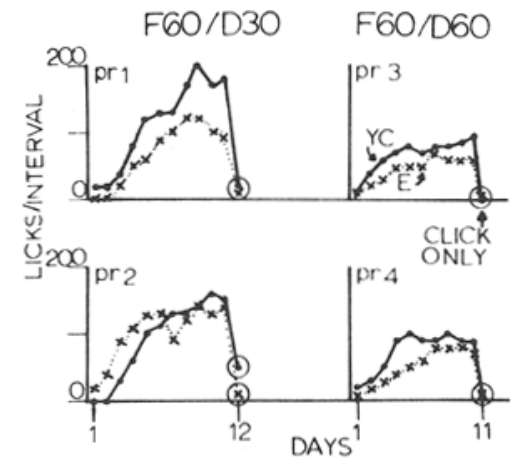

Fig. 2. Mean water licks per interpellet interval in each session. S Pairs 1 and 2 were run on a free-food $60-$ sec schedule with a lick-delay contingency of $30 \mathrm{sec}$ for experimental rats. Pairs 3 and 4 were run on the free-food 60-sec schedule with a lick-delay of $60 \mathrm{sec}$ for experimental rats. Dashed lines: experimental rats; solid lines: their yoked controls.

does slightly reduce the amount of drinking. The yoked control rats, of course, could experience an occasional correlation of drinking and food, if they happened to be drinking at the moment that the arrival of food, determined by the experimental partner's drinking behavior, occurred.

These data suggest that Falk's finding no difference in polydipsic drinking whether or not a 15-sec lick-delay contingency was in effect does not rule out the possibility that food reinforcement made a minor contribution to the strength of polydipsia in his Ss. Nevertheless, the present data confirm Falk's main conclusion, that adventitious food reinforcement is not a principal factor in the development and maintenance of schedule-induced poly dipsia.

In the final session of Experiment 2 (Session 12 for S Pairs 1 and 2, Session 11 for Pairs 3 and 4) the pellet dispenser was empty, but the empty dispenser operated whenever a pellet would normally have been delivered. The final points in Fig. 2 show that the conditioned stimuli associated with food delivery were not sufficient, in the absence of food itself, to generate polydipsia.

\section{REFERENCES}

BURKS, C. D., HITZING, E. W., \& SCHAEFFER, R.W. Drinking response distributions associated with a $4 \%$ sucrose FFI food schedule. Psy chonomic Science, 1967, 8, 13-14.

CLARK, F. C. Some observations on the adventitious reinforcement of drinking under food reinforcement. Journal of the Experimental Analysis of Behavior, 1962, 5, 61-63.

DEADWYLER, S. A., \& SEGAL, E. F. Determinants of polydipsia: VII. Removing the drinking solution midway through DRL sessions. Psychonomic Science, 1965, 3 185-186.

FALK, J. L. Production of polydipsia in normal rats by an intermittent food schedule. Science, 1961a, 133, 195-196.
FALK, J. L. The behavioral regulation of waterelectroly te balance. Nebrask a symposium on motivation. Lincoln: University of Nebraska Press, 1961b. Pp. 1-33.

FALK, J. L. Studies on schedule-induced polydipsia. In M. J. Way ner (Ed.), Thirst. New York: Pergamon Press, 1964. Pp. 95-116.

FALK, J. L. Analysis of water and $\mathrm{NaCl}$ solution acceptance by schedule-induced polydipsia. Journal of the Experimental Analysis of Behavior, 1966a, 9,111-118.

FALK, J. L. Schedule-induced polydipsia as a function of fixed-interval length. Journal of the Experimental Analysis of Behavior, 1966b, 9, 37-39.

FALK, J. L. The motivational properties of schedule-induced polydipsia. Journal of the Experimental Analysis of Behavior, 1966c, 9, 19-25.

FALK, J. L. Control of schedule-induced polydipsia: Type, size, and spacing of meals. Journal of the Experimental Analysis of Behavior, 1967, 10, 199-206.

FALK, J. L. Conditions producing psychogenic polydipsia in animals. Annals of the New York Academy of Seience, in press.

KAPLAN, J. Temporal discrimination in rats during continuous brain stimulation. Psychonomic Science, 1965, 2, 255-256.

LESTER, D. Self-maintenance of intoxication in the rat. Quarterly Journal of Studies in Alcohol, 1961, 22, 223-231.

MALOTT, R. W., \& CUMMING, W. W. A note on psychogenic polydipsia. Psychonomic Science, $1965,2,241-242$.

SALZBERG, C. L. Polydipsia: A distributional analysis of licking responses as a function of fixed interval length. Unpublished MS Thesis, Florida State University, Tallahassee, 1967.

SALZBERG, C. L., \& SCHAEFFER, R. W. Drinking response distribution associated with the acquisition of schedule-induced polydipsia. Journal of the Experimental Analysis of Behavior, in press.

SCHAEFFER, R. W., \& DIEHL, J. Collateral water drinking in rats maintained on FR food reinforcement schedules. Psychonomic Science, $1966,4,257-258$

SCHAEFFER, R. W., DIEHL, J. C., \& SALZBERG, C. L. An application of Premack's theory to behaviors associated with a FFI food schedule. Psychonomic Science, 1966, 6, 405-406.

SCHUSTER, C. R., \& WOODS, J. H. Regimeninduced polydipsia in the rhesus monkey. Paper read at the Eastern Psychological Association meeting, Atlantic City, April, 1965.

SEGAL, E. F. The interaction of psychogenic polydipsia with wheel running in rats. Psychonomic Science, in press.

SEGAL, E. F., \& BANDT, W. M. Influence of collateral water drinking on bar pressing under complex reinforcement contingencies. Psychonomic Science, 1966, 4, 377-378.

SEGAL, E. F., \& HOLLOWAY, S. M. Timing behavior in rats with water drinking as a mediator. Science, 1963, 140, 888-889.

SEGAL, E. F., ODEN, D. L., \& DEADWYLER, S. A. Determinants of polydipsia: IV. Freereinforcement schedules. Psychonomic Science, $1965,3,11 \cdot 12$.

STEIN, L. Excessive drinking in the rat: Superstition or thirst? Joumal of Comparative \& Physiological Psy chology, 1964, 58, 237-242.

\section{NOTE}

1. This work was done at San Diego State College, and supported by Grants NSF G 18132 , NSF GB 1605, NSF GB 5777, and NSF GB 7292 from the National Science Foundation, and Grant NIMH 8505 from the National Institute of Mental Health. 